\title{
Multidisciplinary, Multi-Institutional Consensus on Cetuximab Usefulness in the Treatment of Patients with Head and Neck Squamous Cell Carcinoma
}

\author{
Grupo Multidisciplinario de Tumores de Cabeza y Cuello (GMTCC), Sociedad Mexicana \\ de Oncología (SMeO) \\ José Luis Barrera-Franco, Yolanda Bautista-Aragón, José Francisco Gallegos-Hernández*, \\ Martín Granados-García, Héctor Gurrola-Machuca, Alejandro Juárez-Ramiro, \\ Pomponio José Luján-Castilla, Federico Maldonado-Magos, Gabriela Núñez-Guardado \\ and Michelle Aline Villavicencio Queijeiro
}

Hospital de Oncología, CMN SXXI, IMSS, Ciudad de México, México

Received for publication: 11 November 2016; accepted for publication: 25 February 2017

Available online: 4 August 2017

\section{KEYWORDS \\ Cetuximab; \\ Head and neck cancer; \\ Head and neck \\ squamous cell \\ carcinoma}

\begin{abstract}
Epidermal growth factor receptor is preferably expressed in head and neck squa mous cell carcinomas and is a promising therapeutic target. Cetuximab is the only epidermal growth factor receptor-targeted agent that has been approved for the treatment of squamous cell carcinoma. The 2006 FDA-approved indication refers to the use of cetuximab in com bination with radiotherapy for the treatment of locoregional, advanced, unresectable head and neck squamous cell carcinoma, except for nasopharyngeal carcinoma. In 2011, the use of cetuximab in combination with platinum and 5-fluorouracil was approved as first-line treatment for recurrent and/or metastatic head and neck squamous cell carcinoma. In order to homogenize and arrive at a multidisciplinary, multi-institutional consensus based on scientific evidence, a meeting was held where the existing literature was reviewed and the role of cetuximab in the treatment of patients with head and neck squamous cell carcinoma was dis cussed. This work reviews current evidence-based indications for the use of cetuximab in the treatment of patients with head and neck squamous cell carcinoma. (creativecommons.org) licenses/by-nc-nd/4.0/).
\end{abstract}

*E-mail for correspondence: jfgalh61@gmail.com (J.F. Gallegos-Hernández) 


\section{INTRODUCTION}

Cetuximab (CTX) is a chimeric anti-epidermal growth factor receptor (EGFR) IgG1 monoclonal antibody. Binding of the antibody to the receptor blocks endogenous ligands (epiregulin, amphiregulin, betacellulin, transforming growth factor, epidermal growth factor) binding and promotes internalization of the receptor, which leads to EGFR signaling cascade deregulation. The blockade inhibits cell proliferation, angiogenesis, and metastasis and restores apoptosis. At the extracellular level, it promotes immune system cytotoxic cells attack against EGFR-expressing tumor cells, due to the recognition of the IgG1 Fc region by natural killer cells. In combination with radiotherapy (RT), CTX inhibits DNA repair and tumor angiogenesis, while facilitating apoptosis, radio-sensitizing cells at $\mathrm{G} 1$ phase, and reducing radio-resistance of cells at $S$ phase ${ }^{1-3}$.

Head and neck squamous cell carcinoma (HNSCC) treatment of choice has been surgery followed by radiotherapy; however, at locoregionally advanced or inoperable stages, the association of chemotherapy (CT) with RT (CTRT) emerged in the 1990s as an alternative that offered better control than RT alone. Subsequent studies demonstrated that concomitant CTRT had superior outcomes when compared with RT alone, with overall survival (OS) improvement in patients with unresectable tumors, in patients at high risk or relapse after surgery, and as a non-surgical conservative option of choice for advanced laryngeal and pharyngeal tumors candidate for laryngectomy. However, toxicity emerged as a limitation for systematic administration in patients who are often fragile and with serious comorbidities. Knowledge of the receptors and signaling pathways involved in the genesis and progression of HNSCC led to the development of anti-EGFR monoclonal antibodies and tyrosine kinase-inhibiting molecules. Cetuximab, a monoclonal antibody, has been tested in associations with CT and RT, and has demonstrated activity with a favorable toxicity profile. The indication approved by the FDA in 2006 refers to the use of CTX in combination with RT for the treatment of locoregionally advanced, unresectable HNSCC, except for nasopharyngeal carcinoma, in disease persisting to other treatments, in organ-preservation attempts (larynx), and concomitantly with RT in locoregionally advanced disease. In 2011, the use of CTX was approved in combination with platinum and 5-fluorouracil (5-FU) as first-line treatment for recurrent and/or metastatic HNSCC. This work reviews current indications, based on existing evidence, for the use of CTX in the treatment of patients with HNSCC.

\section{MATERIALS AND METHODS}

A panel comprised of 11 specialists experienced in the treatment of head and neck cancer from different disciplines and who represented health institutions that treat the largest numbers of HNSCC patients in Mexico was integrated with three medical oncologists, four radio-oncologists, and four surgical oncologists, who gathered in Mexico City on May 2, 2016. The meeting was moderated by a medical oncologist. The purpose of the meeting was to generate a diagnosis on current perception on the use of CTX in HNSCC and to arrive to a consensus based on current scientific evidence about

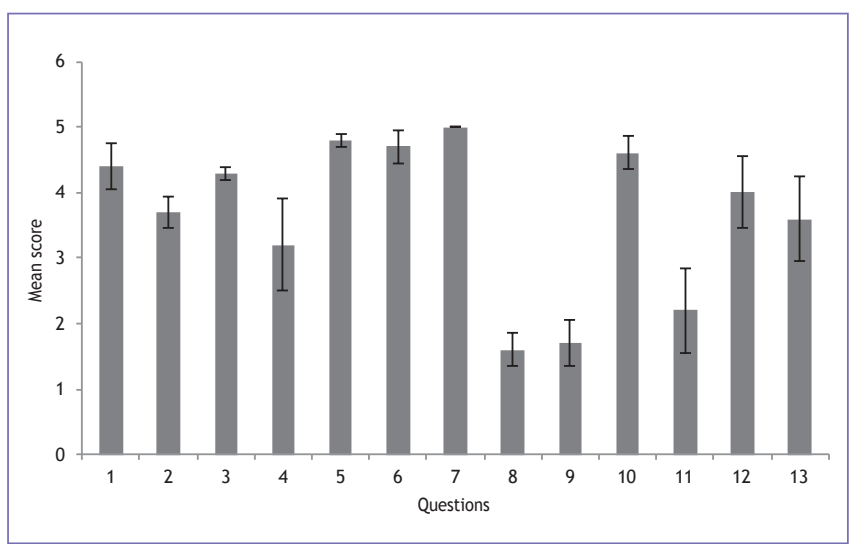

Figure 1. Results of the questionnaire applied in the Advisory Board. Question numbers are associated with table 1. Deviations are represented on each bar.

possible applications of the drug in adherence to the country's characteristics.

Prior to the meeting, the participants answered a 13-question questionnaire (Table 1). The questions were formulated based on a previous literature review. The participants quantified their answers according to a level of agreement disagreement scale from 1-5 (where 1 is total disagreement and 5 is total agreement).

\section{RESULTS}

The results are presented in figure 1 according to table 1 questions.

\section{DISCUSSION}

\section{Question 1: In locally advanced disease, do you consider that cetuximab addition to radiotherapy represents a clinical benefit for the patient?}

Bonner, et al. ${ }^{4}$ conducted a phase III trial to assess CTX associated with RT in patients with locally advanced oro-o pharyngeal, hypopharyngeal, and laryngeal squamous celle carcinoma (SCC), non-candidates for surgery. Patients were randomized to RT and concomitant CTX at weekly standard doses $(n=211)$ vs. RT without CTX $(n=213)$ for $6-7$ weeks. Loco-regional control was 24.4 months in patients with CTX and 14.9 months without CTX $(p=0.005)$. After a 54-month mean follow-up, overall survival (OS) was 49.0 and 29.3 months with and without CTX, respectively $(p=0.03)$, progression-free survival (PFS) was 17.1 and 12.4 months with and without CTX, and, finally, CTX addition decreased the risk for progression $(p=0.006)$ and death by $26 \%$. The study concluded that concomitant treatment with RT and CTX improves locoregional control and reduces mortality without increasing the most common RT-associated adverse events. Five-year OS was 45.6 and $36.4 \%$ in the groups with and without $\mathrm{CTX}^{5}$, respectively. The OS was higher in patients who developed acneform rash (at least grade 2 ) compared 
Table 1. Questions of the Advisory Board questionnaire
1 Efficacy
1.1 In locally advanced disease, do you consider that cetuximab addition to radiotherapy represents a clinical benefit for the patient?
1.2 In locally advanced disease, do you consider the efficacy of cetuximab concomitant with radiotherapy equivalent to chemo-radiotherapy efficacy?
1.3 In locally advanced disease, do you consider there is a benefit when using cetuximab concomitantly with radiotherapy after induction chemotherapy?
1.4 In recurrent/metastatic disease, do you consider the efficacy of cetuximab concomitant with chemotherapy to be equivalent to the efficacy of chemotherapy alone?
2 Toxicity
2.1 In locally advanced and recurrent/metastatic disease, do you consider cetuximab toxicity profile to be predictable and manageable?
2.2 In locally advanced disease, do you consider there are differences in chemo- radiotherapy vs. bio-radiotherapy toxicity profiles?
2.3 In recurrent/metastatic disease, do you consider that cetuximab toxicity profile enables its use as long-term maintenance therapy?
3 Quality of life
3.1 In locally advanced disease, does cetuximab addition to radiotherapy negatively affect patient quality of life?
3.2 In recurrent/metastatic disease, does cetuximab addition to chemotherapy negatively affect patient quality of life?
4 Adherence to therapy
4.1 In locally advanced disease, do you consider the rates of adherence to cetuximab concomitant with radiotherapy more favorable with regard to chemo-radiotherapy?
4.2 In recurrent/metastatic disease, do you consider that cetuximab addition to chemotherapy negatively affects treatment adherence rates?
5 Rescue surgery feasibility
5.1 Do you consider that patients treated with bio-radiotherapy might have more feasibility of rescue and less postoperative complications?
6 Cost-benefit
6.1 In locally advanced disease, do you consider concomitant use of cetuximab with radiotherapy to be cost-beneficial?

to those who developed grade 1 rash or did not experience it at all $(p=0.002)$. This was the first study to demonstrate the additive effects of CTX and RT by improving survival in advanced SCC versus RT alone. By the time the study was published, concomitant CTRT had become the standard of care for unresectable HNSCC. Dattatreya, et al. ${ }^{6}$ recorded 19 unresectable patients treated with CTX/RT, with Bonner's scheme, and observed overall responses (OR) of $68.42 \%$ and two-year OS of $84 \%$. Two years after the protocol was concluded, 13 patients remained free of progression. These results corroborated Bonner's findings. Okano, et al. ${ }^{7}$ assessed CTX with concomitant RT boost in 22 patients with standard-dose CTX for seven weeks and RT at 1.8 Gy once daily for 3.6 weeks, followed by $1.8 \mathrm{~Gy}$ in the morning and $1.5 \mathrm{~Gy}$ at noon for 2.4 weeks. All patients completed at least $70 \%$ of the scheme. At eight weeks, OR was $82 \%$. Table 2 compiles different results of studies with CTX in locally advanced disease. In summary, CTX addition to RT improves OS and locoregional control when compared with RT alone.

\section{Question 2: In locally advanced disease, do you consider the efficacy of cetuximab concomitant with radiotherapy equivalent to chemo-radiotherapy efficacy?}

There are no comparative studies between CTX/RT and high-dose CTRT. Lefebvre, et al. ${ }^{13}$ compared two groups post-induction QT, with 116 cases being analyzed. No significant differences were observed between both groups with regard to larynx preservation (95 vs. 93\%), laryngeal function preservation (87 vs. $82 \%$ ) and OS (92 vs. $89 \%$ ). Levy, et al. ${ }^{23}$ made an indirect comparison in a meta-analysis that included studies of cisplatin plus RT vs. RT alone, and CTX plus RT vs. RT alone. The study failed to find evidence of superiority between CTRT and CTX/RT when locoregionat control and OS outcomes were analyzed. Both treatments can be considered equally efficacious when administered together with RT. Treatment selection can be made based on the toxicity profile. In summary, CTX/RT offers the same possibility of organ preservation as CTRT; however, there are no studies comparing both treatments in locoregionally ad vanced disease.

\section{Question 3: In locally advanced disease, do you consider there is a benefit when using cetuximab concomitantly with radiotherapy after induction chemotherapy?}

Lefebvre, et al. ${ }^{13}$ compared the efficacy and safety of induction CT followed by CTRT or CTX/RT with the purpose of preserving the larynx. Previously untreated patients with stage III or IV larynx/hypolarynx cancer received three induction CT cycles with docetaxel $75 \mathrm{mg} / \mathrm{m}^{2}$ and cisplatin (CDDP), each on day 1 , and $5-\mathrm{FU} 750 \mathrm{mg} / \mathrm{m}^{2}$ on days 1-5. Patients with responses $<50 \%$ underwent laryngectomy. $\mathrm{Pa}$ tients with higher responses were randomized to standard RT (70 Gy) and CDDP (100 mg/m²/day) on days 1,22 , and 43 of RT (group A) or to standard RT and CTX at standard 
Table 2. Cetuximab in locoregionally advanced head and neck squamous cell carcinoma

\begin{tabular}{|c|c|c|c|c|c|c|c|c|c|c|}
\hline \multirow[t]{2}{*}{ (n) } & \multicolumn{3}{|c|}{ Treatment } & \multicolumn{6}{|c|}{ Clinical indicators } & \multirow[t]{2}{*}{ Reference } \\
\hline & Neoadjuvance & First-line & Adjuvance & OR & $\mathrm{CR}$ & PR & OS & PFS & LRC & \\
\hline 47 & $\mathrm{CTX}+\mathrm{P}+\mathrm{Ca}$ & $\begin{array}{l}\text { RT or CTRT } \\
\text { or SX }\end{array}$ & & & $19 \%$ & $77 \%$ & $91 \% 3$ y & $87 \% 3$ y & & Kies, et al. $2010^{8}$ \\
\hline 30 & $\mathrm{CTX}+\mathrm{P}+\mathrm{C}+5-\mathrm{FU}$ & $\mathrm{RT}+\mathrm{C}$ & & & $53 \%$ & & $84 \% 2$ y & $65 \% 2$ y & & Adkins, et al. $2013^{9}$ \\
\hline 22 & $\mathrm{CTX}+\mathrm{D}+\mathrm{C}+5-\mathrm{FU}$ & $\mathrm{RT}+\mathrm{CTX}$ & & & $3 / 18$ & $15 / 18$ & & & & $\begin{array}{l}\text { Charalambakis et al. } \\
2013^{10}\end{array}$ \\
\hline 74 & $\mathrm{CTX}+\mathrm{P}+\mathrm{Ca}$ & $\mathrm{RT}+\mathrm{CTX}+\mathrm{P}+\mathrm{Ca}$ & & & & & $78 \% 3 y$ & $55 \% 3 y$ & & Wanebo, et al. 2014 \\
\hline 39 & $C T X+D+C$ & $\mathrm{RT}+\mathrm{CTX}+\mathrm{C}$ & CTX & & & & $74 \% 3$ y & $70 \% 3 y$ & & Argiris, et al. $2010^{12}$ \\
\hline 211 & & $\mathrm{RT}+\mathrm{CTX}$ & & & & & $49 \mathrm{mo}$ & $17.1 \mathrm{mo}$ & $24.4 \mathrm{mo}$ & Bonner, et al. $2006^{4}$ \\
\hline 19 & & $\mathrm{RT}+\mathrm{CTX}$ & & $68.4 \%$ & & & $84 \% 2$ y & & & $\begin{array}{l}\text { Dattatreya, et al. } \\
2011^{6}\end{array}$ \\
\hline 22 & & $\mathrm{RT}+\mathrm{CTX}$ & & $82 \%$ & & & & & & Okano, et al. $2013^{7}$ \\
\hline 116 & TPF & $\mathrm{RT}+\mathrm{CTX}$ & & & & & $89 \%$ at $18 \mathrm{mo}$ & & & $\begin{array}{l}\text { Lefebvre, et al. } \\
2013^{13}\end{array}$ \\
\hline 49 & TPF & $\mathrm{RT}+\mathrm{CTX}$ & & & $33 / 44$ & & $63 \% 2$ y & $59 \% 2$ y & & Keil, et al. $2013^{14}$ \\
\hline 36 & TPF & $\mathrm{RT}+\mathrm{CTX}$ & & & $60.6 \%$ & $33.3 \%$ & & & & $\begin{array}{l}\text { Rampino, et al. } \\
2012^{15}\end{array}$ \\
\hline 91 & & $\mathrm{RT}+\mathrm{CTX}$ & CTX & & & & & & $59 \% 1 \mathrm{y}$ & Mesía, et al. $2013^{16}$ \\
\hline 20 & & $\mathrm{RT}+\mathrm{CTX}+\mathrm{G}$ & & $100 \%$ & $61.5 \%$ & $38.5 \%$ & $53 \mathrm{mo}$ & & & $\begin{array}{l}\text { Granados, et al. } \\
2011^{17}\end{array}$ \\
\hline \multirow[t]{2}{*}{60} & & $\mathrm{RT}+\mathrm{CTX}+\mathrm{C}$ & CTX & $66.7 \%$ & $39 \%$ & $28 \%$ & $66 \% 2$ y & $47 \% 2$ y & & \\
\hline & & & & & & & & $19.4 \mathrm{mo}$ & & Egloff, et al. $2014^{18}$ \\
\hline \multirow[t]{2}{*}{238} & & $\mathrm{RT}+\mathrm{CTX}+\mathrm{C}$ & & & & & $69 \% 2$ y & $57 \% 2$ y & & Harari, et al. $2014^{19}$ \\
\hline & & $R T+C T X+D$ & & & & & $79 \% 2$ y & $66 \% 2$ y & & \\
\hline 45 & & $\mathrm{RT}+\mathrm{CTX}+\mathrm{C}+5-\mathrm{FU}$ & & & $71 \%$ & & $32.6 \mathrm{mo}$ & $21 \mathrm{mo}$ & & Merlano, et al. $2011^{20}$ \\
\hline 43 & & $\mathrm{RT}+\mathrm{CTX}+\mathrm{P}+\mathrm{Ca}$ & & & $84 \%$ & & $59 \% 3$ y & $58 \% 3$ y & $72 \% 3$ y & $\begin{array}{l}\text { Suntharalinga, et al. } \\
2012^{21}\end{array}$ \\
\hline 33 & & $\mathrm{RT}+\mathrm{CTX}+5-\mathrm{FU}+\mathrm{H}$ & & & & & $86 \% 2$ y & $69 \% 2$ y & $83 \% 2$ y & Kao, et al. $2011^{22}$ \\
\hline
\end{tabular}

5-FU: 5-Fluorouracil; C: cisplatin; Ca: carboplatin; CR: complete response; CTRT: chemo-radiotherapy; CTX: cetuximab; D: docetaxel; G: gemcitabine; H: hydroxyurea; LRC: locoregional control; mo: months; n: patient number; OR: overall response; OS: overall survival;

P: paclitaxel; PFS: progression-free survival; PR: partial response; RT: radiotherapy; SX: surgery; y: years; TPF: taxane, platinum and fluorouracil.

doses during RT (group B). Three months later, organ preservation was assessed, with pharyngeal function and OS being evaluated 18 months later. Out of 153 initial cases, 116 were analyzed. No significant differences were observed between group A and B with regard to larynx preservation (95 vs. $93 \%$ ), laryngeal function preservation (87 vs. $82 \%$ ) and OS (92 vs. $89 \%$ ), respectively. However, treatment tolerance was superior with CTX/RT, and rescue surgery was feasible only in patients treated with CTX/RT. CTRT acute toxicity generated more protocol changes in comparison with CTX/ RT. In the CTRT group, $22.4 \%$ of patients developed chronic renal toxicity. With regard to treatment compliance, $42 \%$ of patients received all three CDDP planned cycles in group $A$, and $71 \%$ of patients received all seven CTX planned cycles in group $B$. The study corroborated the favorable toxicity profile of the CTX-scheme, as well as higher rates of compliance, and failed to demonstrate clinical superiority of CTRT over CTX/RT. Two additional studies explored the efficacy of induction CT followed by CTX/RT with CTX. Keil, et al. ${ }^{14}$ assessed 49 patients who received three induction
CT cycles: docetaxel $\left(75 \mathrm{mg} / \mathrm{m}^{2}\right), \operatorname{CDDP}\left(75 \mathrm{mg} / \mathrm{m}^{2}\right)$ on day 1 , and $5-\mathrm{FU}\left(750 \mathrm{mg} / \mathrm{m}^{2} /\right.$ day $)$ on days 1 through 5 , followed by CTX/RT with CTX at standard weekly doses. Forty-fouro patients received RT plus CTX. At three months, complete response $(C R)$ was observed in 33 patients. Two years later; 25 patients remained with CR. Two-year PFS was 59\% and two-year OS was $63 \%$. The most common adverse effects were radiodermatitis (30\%), mucositis $(27 \%)$, and non-febrile neutropenia (17\%). Rampino, et al. ${ }^{15}$ also assessed two cycles of docetaxel, CDDP, and 5-FU followed by CTX/RT. In 36 stage III and IV patients, CR was $60.6 \%$ and partial response (PR) was $33.3 \%$. Toxicity included febrile neutropenia $(6 \%)$ during induction, and dermatitis (48\%), mucositis (33\%), and dysphagia (12\%) during the CTX/RT phase. In summary, CTX/ RT after induction CT in responders with organ-preservation attempt offers the same results as CTRT, with a better safety profile and higher treatment adherence. In addition, rescue surgery in patients failing after CTX/RT has higher rates of success and lower rates of complications than that in patients treated with concomitant CT and RT. 
Table 3. Cetuximab in recurrent/metastatic head and neck carcinoma

\begin{tabular}{|c|c|c|c|c|c|c|c|c|}
\hline \multirow[t]{2}{*}{ (n) } & \multirow[t]{2}{*}{ Treatment } & \multicolumn{6}{|c|}{ Clinical indicators } & \multirow[t]{2}{*}{ Reference } \\
\hline & & OR & CR & PR & OS & PFS & LRC & \\
\hline 117 & $C+C T X$ & 26 & & & $9.2 \mathrm{mo}$ & $4.2 \mathrm{mo}$ & & Burtness, et al. $2005^{29}$ \\
\hline 96 & $\mathrm{C}+\mathrm{CTX}$ & & 10 & & $6.1 \mathrm{mo}$ & $2.8 \mathrm{mo}$ & $53 \%$ & Baselga, et al. $2005^{30}$ \\
\hline 222 & $\begin{array}{l}\mathrm{C} \text { or } \mathrm{Ca}+5- \\
\mathrm{FU}+\mathrm{CTX}\end{array}$ & & 36 & & $10.1 \mathrm{mo}$ & $5.6 \mathrm{mo}$ & & Vermorken, et al. $2008^{31}$ \\
\hline 121 & $\mathrm{C}+5-\mathrm{FU}+\mathrm{CTX}$ & 24 & & & $11.0 \mathrm{mo}$ & $8.0 \mathrm{~m}$ & $48.9 \%$ & De Mello, et al. $2014^{28}$ \\
\hline 33 & $\mathrm{C}+5-\mathrm{FU}+\mathrm{CTX}$ & 36 & & & $14.1 \mathrm{mo}$ & $4.1 \mathrm{mo}$ & $88 \%$ & Yoshino, et al. $2013^{26}$ \\
\hline 68 & $\mathrm{C}+5-\mathrm{FU}+\mathrm{CTX}$ & 56 & & & $12.6 \mathrm{mo}$ & $6.6 \mathrm{mo}$ & & Guo, et al. $2014^{27}$ \\
\hline 46 & $\mathrm{P}+\mathrm{CTX}$ & 54 & 22 & 32 & $8.1 \mathrm{mo}$ & $4.2 \mathrm{mo}$ & $80 \%$ & Hitt, et al. $2012^{32}$ \\
\hline 22 & $\mathrm{P}+\mathrm{CTX}$ & 55 & & & $9.1 \mathrm{mo}$ & $5.4 \mathrm{mo}$ & & Jimenez, et al. $2013^{33}$ \\
\hline 42 & $\mathrm{P}+\mathrm{CTX}$ & 38 & & & $7.6 \mathrm{mo}$ & $3.9 \mathrm{mo}$ & $74 \%$ & Perón, et al. $2012^{34}$ \\
\hline 84 & $C T X+D$ & & & 11 & $6.7 \mathrm{mo}$ & $3.1 \mathrm{mo}$ & $51 \%$ & Knoedler, et al. $2013^{35}$ \\
\hline 54 & $C+D+C T X$ & 44 & & & $14 \mathrm{mo}$ & $6.2 \mathrm{mo}$ & & Guigay, et al. $2015^{36}$ \\
\hline 73 & $\mathrm{RT}+\mathrm{CTX}$ & 59.4 & & & $18 \mathrm{mo}$ & $15 \mathrm{mo}$ & & Jensen, et al. $2010^{37}$ \\
\hline 18 & $\mathrm{RT}+\mathrm{CTX}$ & 47 & & & $\begin{array}{l}8.3 \mathrm{mo} \\
44 \% 1 \mathrm{y}\end{array}$ & $7.3 \mathrm{mo}$ & $33 \% 1 y$ & Balermpas, et al. $2012^{38}$ \\
\hline 70 & $\mathrm{RT}+\mathrm{CTX}$ & & & & $24.5 \mathrm{mo}$ & & & Heron, et al. $2011^{39}$ \\
\hline 60 & $\mathrm{RT}+\mathrm{CTX}$ & 58.4 & & & $47.5 \% 1 \mathrm{y}$ & & $91.7 \%$ & Lartigau, et al. $2013^{40}$ \\
\hline 50 & $\mathrm{RT}+\mathrm{CTX}$ & & & & $\begin{array}{c}10 \mathrm{mo} \\
40 \% 1 \mathrm{y}\end{array}$ & $33 \% 1 \mathrm{y}$ & & Vargo, et al. $2015^{41}$ \\
\hline 28 & $\mathrm{RT}+\mathrm{CTX}$ & & & & $641 \mathrm{y}$ & $491 \mathrm{y}$ & $51 \% 1 \mathrm{y}$ & Vargo, et al. $2014^{42}$ \\
\hline
\end{tabular}

5-FU: 5-Fluorouracil; C: cisplatin; Ca: carboplatin; CR: complete response; CTRT: chemo-radiotherapy; CTX: cetuximab; D: docetaxel; G: gemcitabine; H: hydroxyurea; LRC: locoregional control; mo: months; n: patient number; OR: overall response; OS: overall survival;

P: paclitaxel; PFS: progression-free survival; PR: partial response; RT: radiotherapy; SX: surgery; y: years; TPF: taxane, platinum and fluorouracil.

\section{Question 4: In recurrent/metastatic disease, do you consider the efficacy of cetuximab concomitant with chemotherapy to be equivalent to the efficacy of chemotherapy alone?}

The European Society for Medical Oncology (ESMO) and National Comprehensive Cancer Network (NCCN) international guidelines support the use of CTX as first-line treatment in patients with persistent, recurrent/metastatic disease. The pivotal study was coordinated by Vermorken, et al. As a previous exercise in $2007^{24}$, his group assessed the feasibility and safety of CTX monotherapy at usual doses for six weeks in patients progressing on platinum-based therapy (2-6 cycles). Out of 103 patients whose disease progressed, 53 received CTX with or without platinum. With monotherapy, response rate was $13 \%$, disease control $46 \%$, and time to progression was 70 days. With combined therapy, OR was zero, disease control occurred in $26 \%$, and time to progression was 50 days; OS reached 178 days. This study showed that single-drug CTX is active and well tolerated. One year later, the same author ${ }^{25}$ published the phase III EXTREME trial. The study enrolled 422 patients with untreated recurrent/ metastatic SCC; half of them received CDDP $\left(100 \mathrm{mg} / \mathrm{m}^{2}\right)$ on day 1 , or carboplatin $(A U C=5)$ plus $5-F U\left(1000 \mathrm{mg} / \mathrm{m}^{2} /\right.$ day $)$ during four days every three weeks for a maximum of six cycles. The remaining patients received the same CT plus
CTX at standard doses for a maximum of six cycles. Patients with stable disease (SD) on treatment with CT plus CTX continued with CTX until progression or unacceptable toxicity. The study demonstrated that CTX addition to CDDP or carboplatin and 5-FU significantly improves response with regard to CT alone. Addition of CTX prolonged OS from 7.4 to 10.1 months ( $p=0.04$ ), PFS from 3.3 to 5.6 months $(p<0.001)$ and increased the response rate from 20 to $36 \%(p<0.001)$. Finally, the addition of CTX decreased the risk of death by $20 \%$. Treatment duration with CTX was 18 weeks. The CTX relative dose intensity (RDI) was higher than $80 \%$ in 84 and $82 \%$ of patients at first phase of therapy and at follow-up, respectively. This was the first randomized trial to demonstrate benefit when adding a new drug to CDDP-based therapy over CT alone, thus concluding that the addition of CTX to platinum and 5-FU-based CT increases OS as first-line in patients with recurrent/metastatic HNSCC. The triple combination of CTX, CDDP, and 5-FU has been re peatedly assessed. Yoshino, et al. ${ }^{26}$ assessed the CTX, CDDP, and 5-FU combination as first-line therapy in metastatic recurrent SCC, using CTX at standard weekly doses, CDDP at $100 \mathrm{mg} / \mathrm{m}^{2}$ on day 1 , and 5 -FU at $1000 \mathrm{mg} / \mathrm{m}^{2} /$ day on days 1 through 4 , for a maximum of six cycles. The OR rate was $36 \%$, disease control rate was $88 \%$, and PFS and OS were 4.1 and 14.1 months, respectively. With the same protocol, Guo, et al. ${ }^{27}$ explored the addition of CTX to cisplatin and 5-FU-based CT in 68 Asian patients. The OR rate was 55.9\%, including two complete responses. The OS was 12.6 months 
Table 4. Management strategies for patients developing radiodermatitis while on treatment with cetuximab plus radiotherapy

\begin{tabular}{|c|c|c|c|}
\hline & Grade II & Grade III & Grade IV \\
\hline \multirow{3}{*}{$\begin{array}{l}\text { Follow-up/ } \\
\text { Continuity* }\end{array}$} & Twice-weekly. & Assess the need for daily follow-up. & \multirow{19}{*}{$\begin{array}{l}\text { Continuous follow-up. } \\
\text { Cetuximab should be interrupted } \\
\text { until skin reactions resolve } \\
\text { to at least grade II. } \\
\text { In case of severe infection, } \\
\text { consider the use of IV antibiotics } \\
\text { in the absence of response } \\
\text { to oral therapy. } \\
\text { Hospitalize the patient. }\end{array}$} \\
\hline & Continue treatment. & $\begin{array}{l}\text { Frequent monitoring looking for } \\
\text { signs of local or systemic infection. } \\
\text { In case of reaction occurring with }\end{array}$ & \\
\hline & & $\begin{array}{l}\text { doses } \geq 50 \text { Gy, consider brief } \\
\text { interruption. }\end{array}$ & \\
\hline \multirow[t]{16}{*}{ Management } & \multirow{6}{*}{$\begin{array}{l}\text { 1. Dry desquamation without scales: } \\
\text { Corticosteroid-based creams or } \\
\text { ointments for a limited period } \\
\text { (1-2 weeks). } \\
\text { In the presence of signs of } \\
\text { infection, topical antiseptics and } \\
\text { antibiotics. Consider them for } \\
\text { prevention of more severe } \\
\text { reactions. }\end{array}$} & $\begin{array}{l}\text { 1. Confluent moist desquamation } \\
\text { without scales: }\end{array}$ & \\
\hline & & & \\
\hline & & $\begin{array}{l}\text { daily application to reduce } \\
\text { inflammation for a limited period } \\
\text { (1-2 weeks). }\end{array}$ & \\
\hline & & $\begin{array}{l}\text { Topical antibiotics against } \\
\text { Staphylococcus aureus in case } \\
\text { of any sign of infection. }\end{array}$ & \\
\hline & & $\begin{array}{l}\text { If the infection increases in } \\
\text { intensity, consider the use of } \\
\text { IV antibiotics in the absence } \\
\text { of response to oral therapy. }\end{array}$ & \\
\hline & & $\begin{array}{l}\text { Eosin or zinc preparations on } \\
\text { folds. }\end{array}$ & \\
\hline & $\begin{array}{l}\text { 2. Moist desquamation in folds: } \\
\text { Topical antiseptic. }\end{array}$ & \multirow{10}{*}{$\begin{array}{l}\text { 2. Confluent moist desquamation } \\
\text { with scales: } \\
\text { Topical antiseptic. } \\
\text { If the infection increases in } \\
\text { intensity, consider the use of } \\
\text { IV antibiotics in the absence } \\
\text { of response to oral therapy. } \\
\text { Consider debridement with } \\
\text { hydrogels. Avoid trauma to } \\
\text { prevent infections. } \\
\text { If hydrocolloid dressings are } \\
\text { used, dressing thickness should } \\
\text { be considered in RT dosimetry. } \\
\text { Hydrofiber dressings can be used } \\
\text { after RT completion. }\end{array}$} & \\
\hline & $\begin{array}{l}\text { Consider topical corticosteroids } \\
\text { daily application to reduce } \\
\text { inflammation for a limited period } \\
(1-2 \text { weeks). }\end{array}$ & & \\
\hline & Topical antibiotics against & & \\
\hline & $\begin{array}{l}\text { Staphylococcus aureus if there are } \\
\text { signs of infection. Consider } \\
\text { systemic antibiotics in case of }\end{array}$ & & \\
\hline & more severe infection. & & \\
\hline & $\begin{array}{l}\text { Eosin or zinc preparations on } \\
\text { folds. }\end{array}$ & & \\
\hline & $\begin{array}{l}\text { 3. Dry desquamation with isolated, } \\
\text { non-hemorrhagic scales: }\end{array}$ & & \\
\hline & Topical antiseptics. & & \\
\hline & $\begin{array}{l}\text { Consider topical corticosteroids } \\
\text { daily application to reduce } \\
\text { inflammation for a limited period } \\
(1-2 \text { weeks). }\end{array}$ & & \\
\hline & $\begin{array}{l}\text { Topical antibiotics against } \\
\text { Staphylococcus aureus if there are } \\
\text { signs of infection. Consider } \\
\text { systemic antibiotics in case of } \\
\text { more severe infection. }\end{array}$ & & \\
\hline
\end{tabular}

and PFS was 6.6 months. De Mello, et al. ${ }^{28}$ retrospectively assessed 121 patients who received CDDP plus 5-FU and CTX every three weeks for a maximum of six cycles. Patients with stable disease continued to receive CTX until progression or unacceptable toxicity. The addition of CTX led to an OS of 11 months and PFS of eight months. The disease control rate was $48.9 \%$ and OR rate was $23.91 \%$. Table 3 compiles different results of trials with CTX in recurrent/ metastatic disease. In summary, the highest response rate and the best control are obtained in patients receiving the 
Table 5. Some considerations on education for patients with radiodermatitis associated with radiotherapy and cetuximab

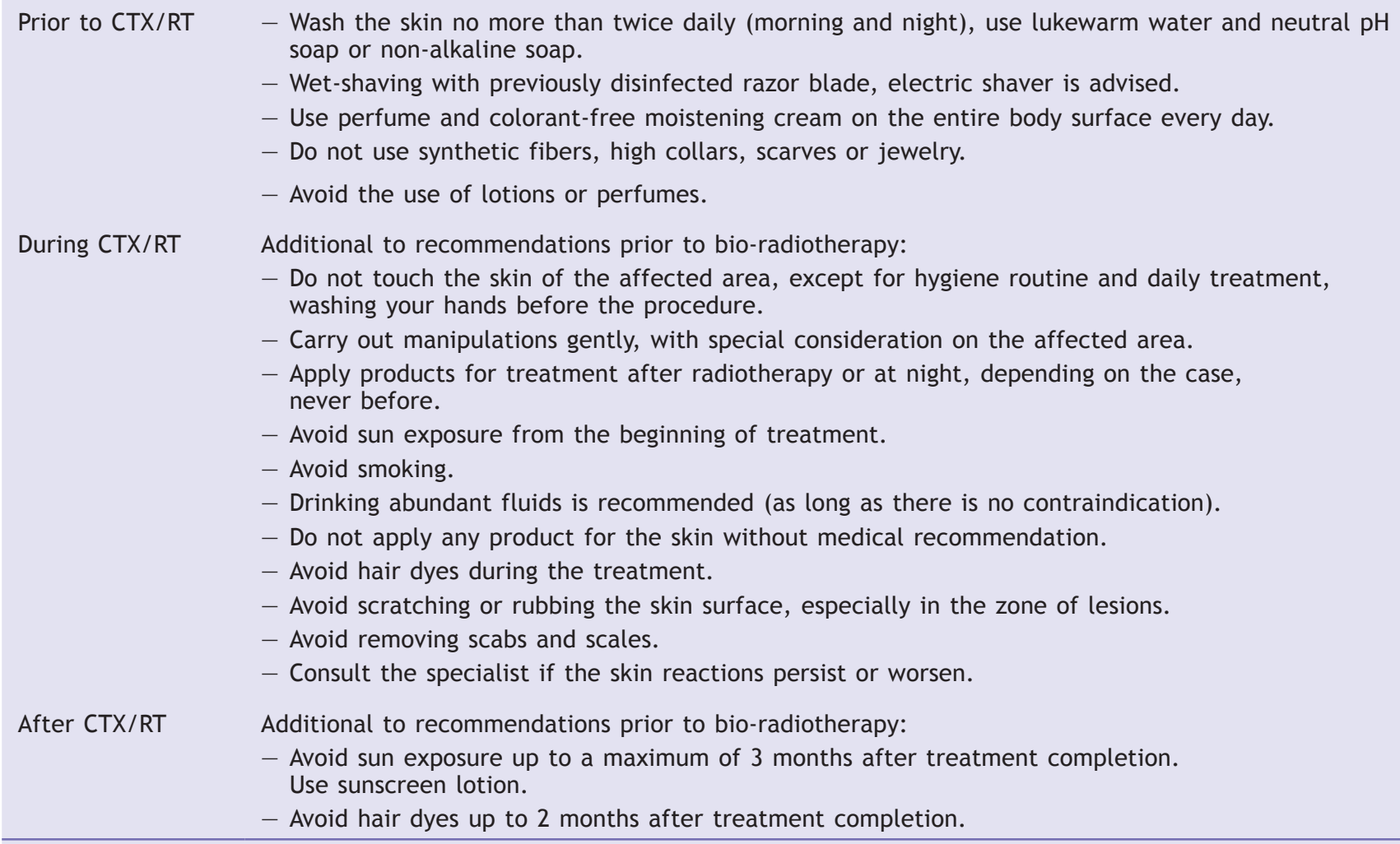

CTX: cetuximab; RT: radiotherapy.

CT/CTX association, with this association therefore being the treatment of choice in recurrent/metastatic disease.

\section{Question 5: In locally advanced and recurrent/metastatic disease, do you consider the cetuximab toxicity profile to be predictable and manageable?}

Although in CTX/RT-treated patients dermatitis intensity is higher and appears earlier in comparison to RT alone, resolution times are shorter, treatment compliance rates are higher, and skin sequels such as scars generally do not persist. In summary, currently available information allows concluding that bio-radiotherapy-associated dermatitis is a predictable, manageable, and reversible event, the correct management of which does not affect treatment continuity or clinical outcome. Tables 4 and 5 summarize considerations on management and patient education exposed by Russi, et al. ${ }^{43}$ and Bernier, et al. ${ }^{44}$.

\section{Question 6: In locally advanced disease, do you consider there are differences in chemo-radiotherapy vs. bio-radiotherapy toxicity profiles?}

Lefebvre, et al. ${ }^{13}$ compared the efficacy and safety of induction CT followed by CTRT or CTX/RT for larynx preser- vation. There were no differences in grade 3 or 4 mucositis between groups, and the CTX/RT group had more grade 3 and 4 skin reactions. The CTRT group showed more renal and hematologic toxicity and decreased functional activity leading to more protocol modifications owing to acute toxicity (57 vs. $34 \%$ ). With regard to late toxicity (at least six months after treatment completion), CTRT led to more renal dysfunction (22.4 vs. $0 \%)$. Taberna, et al. ${ }^{45}$ identified CTRT as a risk factor for moderate (odds-ratio [OR]: 0.292; 95\% confidence interval [CI]: 0.125-0.680; $\mathrm{p}=0.004$ ) and severe late toxicity (OR: $0.299 ; 95 \% \mathrm{Cl}: 0.0909-0.999$; $\mathrm{p}=0.05$ ) in comparison with CTX/RT. In summary, patients treated with CTRT with CDDP show higher rates of chronic; severe and irreversible toxicity in comparison with patients treated with CTX/RT.

\section{Question 7: In recurrent/metastatic disease, do you consider that the cetuximab toxicity profile permits its use as long-term maintenance therapy?}

With the EXTREME scheme, the incidence of grade 3 or 4 adverse events was similar between the compared groups (CTX/CT and CT alone), except for skin reactions ( 9 vs. $1 \%$ ), hypomagnesemia ( 5 vs. $1 \%$ ) and sepsis ( 4 vs. $1 \%$ ), with greater effects associated with $\mathrm{CTX}^{31}$. In summary, in recurrent and/or metastatic disease, CTX-produced toxicity is not maintenance-treatment limiting. 


\section{Question 8: In locally advanced disease, does cetuximab addition to radiotherapy negatively affect patients' quality of life?}

Curran, et al. ${ }^{46}$ assessed Bonner's study patients' quality of life using the European Organization for Research and Treatment of Cancer (EORTC) quality of life QLQ-C30 and head and neck QLQ-35 questionnaires at treatment initiation and at 1, 4, 8, and 12 months. Out of 424 patients, 213 received RT alone and 211 RT plus CTX. The CTX/RT improved locoregional control $(p=0.005)$ and OS $(p=0.03)$ vs. RT alone, with no significant differences in quality of life. In summary, CTX addition does not affect quality of life.

\section{Question 9: In recurrent/metastatic disease, does cetuximab addition to chemotherapy negatively affect patient quality of life?}

Mesía, et al. ${ }^{47}$ examined treatment impact on quality of life in patients participating in Vermorken's study, according to EORTC criteria (QLQ-30 quality of life and QLQ-35 head and neck questionnaires). Out of 442 randomized patients, 291 completed the questionnaires. The study concluded that the addition of CTX to platinum and 5-FU-based CT does not worsen quality of life; in fact, better quality of life/health global status was demonstrated $(p=0.041)$, with no difference in the social functioning scale, and better control of pain and swallowing problems. In summary, cetuximab addition to chemotherapy not only does not decrease quality of life, but improves it by decreasing neoplasm-associated symptom intensity.

\section{Question 10: In locally advanced disease, do you consider the rates of adherence to cetuximab concomitant with radiotherapy more favorable with regard to chemo- radiotherapy?}

In the study of Bonner, et al. ${ }^{4}, 90 \%$ of patients received all eight planned doses. Similarly, an important aspect to be highlighted in the study of Lefebvre, et al. ${ }^{13}$ is the compliance rates, where the percentage of patients who completed the initially planned dose was $43 \%$ in the group of patients with CTRT and $71 \%$ in the CTX/RT group. The protocol was modified due to acute toxicity in $57 \%$ of patients with CTRT and in 34\% with CTX/RT. Another study with larynx-preservation purposes using neoadjuvant $C T$ with docetaxel, CDDP and 5-FU followed by CTX/RT or CTRT, revealed higher rates of compliance with the use of CTX/ RT $(79.5 \%)$ vs. CTRT with CDDP $(51.7 \%)^{48}$. In contrast, the number of patients receiving therapy with CDDP has been observed to decrease with increasing treatment duration: using a CTRT scheme (CDDP $100 \mathrm{mg} / \mathrm{m}^{2} \mathrm{q} 3 \mathrm{wk}$ ), compliance rates of 88,66 and $49 \%$ were obtained at first, second, and third cycle of treatment, respectively ${ }^{49}$. In summary, treatment adherence rates are higher with CTX than with chemotherapy.
Question 11: In recurrent/metastatic disease, do you consider that cetuximab addition to chemotherapy negatively affects treatment adherence rates?

In the EXTREME trial ${ }^{31}, 84 \%$ of patients receiving CTX after initial loading dose recorded a relative dose intensity (RDI) of $80 \%$ or higher, and $82 \%$ of patients reported an equal RDI in the maintenance phase. Patients in the CTX group received a mean of five CT cycles, and patients in the CT alone group, four cycles. For $89 \%$ of patients in the CTX group and $86 \%$ in the CT alone group, RDI was $80 \%$ or higher. Similarly, the GORTEC study ${ }^{36}$ reported a RDI of $80 \%$ or higher in $84 \%$ of patients, and $79 \%$ of patients initiated the maintenance phase, During that phase, RDI for CTX was close to $100 \%$; mean duration of the maintenance phase was $4.6 \pm 4.5$ months. One patient was treated with CTX during maintenance for a period longer than 22 months. In summary, adherence rates were similar to those for CT in both groups, suggesting that CTX addition did not affect standard treatment tolerance.

\section{Question 12: Do you consider that patients treated with bio-radiotherapy have better chances for surgical rescue and less postoperative complications?}

Lefebvre, et al. ${ }^{13}$ showed that rescue surgery was possible only in patients undergoing CTX/RT after induction CT. León, et al. ${ }^{50}$ recorded the clinical response and surgical compli=cations after rescue surgery due to relapse after CTRT ( $\mathrm{n}=$ $154)$ or CTX/RT $(n=33)$. The CTX/RT-treated patients had higher mean age and ECOG with regard to CTRT-treated patients; $37.2 \%$ of patients with CTRT and $61.5 \%$ with CTX/RT underwent rescue surgery. A multivariate analysis demonstrated that the surgical rescue-associated variable with more weight was initial treatment. The frequency of postop erative complications was higher among those who received CTRT (62.5\%) in comparison with CTX/RT (12.5\%). Five-year OS after rescue surgery was $26.0 \%$ for patients who received CTRT and $70.0 \%$ for those with CTX/RT. In summary, patients with recurrence after CTX/RT were better candidates for rescue surgery than those who had been treated with $\mathrm{CT} / \mathrm{S}$ RT, with a lower rate of postoperative complications and better OS.

Question 13: In locally advanced disease, do you consider concomitant use of cetuximab with radiotherapy to be cost-beneficial?

In locoregionally advanced carcinomas, the CTX/RT scheme is cost effective. Brown, et al. ${ }^{51}$ estimated CTX/RT cost-effectiveness in comparison with RT alone. Independent economic analyses were carried out in Belgium, France, Italy, Switzerland, and the UK, with the economic model being based on patient data extracted from Bonner's study. Each country's specific costs of care came from official sources. Panels of clinical experts estimated the resources and validated the assumptions employed to extrapolate costs and health outcomes. In the analysis, incremental cost per quality-adjusted life year (QALY) for patients receiving CTX/RT 
vs. RT alone among all countries was $€ 7,538$ to 10,836 . This cost-effectiveness analysis indicated that CTX addition offers a good value/price alternative compared to RT alone. Another pharmacoeconomic study supports the concomitant use of CTX with RT. To estimate the real-world incremental cost per QALY with the CTX/RT scheme vs. RT alone as firstline treatment, a Markov model was constructed with the following classifications: "alive without progression", "alive with progression", and "deceased". One-month transition probabilities were estimated based on clinical trial data and retrospective real-world data from two Dutch head and neck cancer centers $(2007-2010, n=141)$. Incremental costs per gained QALY range from $€ 14,624$ to 38,543 , and acceptability curves for different scenarios show probabilities ranging from 0.76 to 0.87 , with CTX/RT being cost-effective in comparison with RT alone. In summary, current results show that CTX/RT combination treatment is a cost-effective treatment option for patients with locally advanced HNSCC ${ }^{52}$.

Note: In different institutions of Mexico's health sector, the heterogeneous availability of different therapies complicates both first-line and second-line treatment of patients with head and neck cancer. The largest experience has been obtained from patients with locally advanced, unresectable disease that are not amenable for CTRT, and from the rescue attempt of patients with persistent or metastatic disease, not candidates for other treatments. This is why inter-institutional opinion differs with regard to availability of therapies and optimal timing for their use. The present consensus was based on worldwide recommendations based on updated scientific evidence.

\section{CONCLUSIONS}

Cetuximab is an alternative in the therapeutics of cancer originating in the mucous membranes of the head and neck area. In locoregionally advanced disease, CTX associated with RT is superior to RT alone, without an important increase in toxicity and less morbidity than the CTRT association. The CTX/RT treatment offers similar OS and locoregional control to the CTRT association, with less toxicity and higher treatment adherence, and in case rescue surgery is required, it can be accomplished more often and with lower morbidity than in CTRT-treated patients.

In patients treated with organ-preservation attempts, especially in those with laryngeal cancer in whom total laryngectomy is indicated owing to the extension of the neoplasm, CTX/RT in those showing complete response to induction CT offers similar results as CTRT, with less toxicity, higher treatment adherence, and higher possibility of surgical rescue if required. Bio-radiotherapy is an option as initial treatment in patients in whom tumor recurrence can be expected (organ preservation, mainly oral cavity and hypopharynx), with the purpose to facilitate surgical rescue if required and reduce morbidity. In recurrent/metastatic disease, CTX addition to platinum-based therapy is the option that offers the largest number of responses, without therapy tolerance and patient quality of life being affected, which is why it is considered the treatment of choice.

\section{DECLARATION OF INTEREST}

The May 2, 2016 meeting was financed by Merck Serono.

\section{REFERENCES}

1. Vincenzi B, Schiavon G, Silletta M, Santini D, Tonini G. The biological properties of cetuximab. Crit Rev Oncol Hematol. 2008;68:93-106.

2. Huang SM, Harari PM. Modulation of radiation response after epidermal growth factor receptor blockade in squamous cell carcinomas: inhibition of damage repair, cell cycle kinetics, and tumor angiogenesis. Clin Cancer Res. 2000;6:2166-74.

3. Gerber DE, Choy H. Cetuximab in combination therapy: from bench to clinic. Cancer Metastasis Rev. 2010;29:171-80.

4. Bonner JA, Harari PM, Giralt J, et al. Radiotherapy plus cetuximab for squamous-cell carcinoma of the head and neck. N Engl J Med 2006;354:567-78.

5. Bonner JA, Harari PM, Giralt J, et al. Radiotherapy plus cetuximab for locoregionally advanced head and neck cancer: 5-year survival data from a phase 3 randomised trial, and relation between cetuximab-induced rash and survival. Lancet Oncol. 2010;11:21-8.

6. Dattatreya S, Goswami C. Cetuximab plus radiotherapy in patients with unresectable locally advanced squamous cell carcinoma of head and neck region-a open labelled single arm phase II study. Indian J Cancer. 2011;48:154-7.

7. Okano S, Yoshino T, Fujii M, et al. Phase II study of cetuximab plus concomitant boost radiotherapy in Japanese patients with locally advanced squamous cell carcinoma of the head and neck. Jpn J Clin Oncol. 2013;43:476-82.

8. Kies MS, Holsinger FC, Lee JJ, et al. Induction chemotherapy and cetux imab for locally advanced squamous cell carcinoma of the head and neck: results from a phase II prospective trial. J Clin Oncol. 2010;28:8-14.

9. Adkins D, Ley J, Trinkaus K, et al. A phase 2 trial of induction nab-paclitaxel and cetuximab given with cisplatin and 5-fluorouracil followed by concurrent cisplatin and radiation for locally advanced squamous cell carcinoma of the head and neck. Cancer. 2013;119:766-73.

10. Charalambakis $\mathrm{N}$, Kouloulias V, Vaja H, et al. Feasibility of induction docetaxel, cisplatin, 5-fluorouracil, cetuximab (TPF-C) followed by concurrent cetuximab radiotherapy for locally advanced head and neck squamous cell carcinoma. Front Oncol. 2013;3:5.

11. Wanebo HJ, Lee J, Burtness BA, et al. Induction cetuximab, paclitaxel, and carboplatin followed by chemoradiation with cetuximab, paclitaxel, and carboplatin for stage III/IV head and neck squamous cancer: a phase II ECOG-ACRIN trial (E2303). Ann Oncol. 2014;25:2036-41.

12. Argiris A, Heron DE, Smith RP, et al. Induction docetaxel, cisplatin, and cetuximab followed by concurrent radiotherapy, cisplatin, and cetuximab and maintenance cetuximab in patients with locally advanced head and neck cancer. J Clin Oncol. 2010;28:5294-300.

13. Lefebvre JL, Pointreau $\mathrm{Y}$, Rolland Fet al. Induction chemotherapy followed by either chemoradiotherapy or bioradiotherapy for larynx preservation: the TREMPLIN randomized phase II study. J Clin Oncol. 2013;31:853-9.

14. Keil F, Selzer E, Berghold A, et al. Induction chemotherapy with docetaxel, cisplatin and 5-fluorouracil followed by radiotherapy with cetuximab for locally advanced squamous cell carcinoma of the head and neck. Eur J Cancer. 2013;49:352-9.

15. Rampino $M$, Bacigalupo A, Russi $E$, et al. Efficacy and feasibility of induction chemotherapy and radiotherapy plus cetuximab in head and neck cancer. Anticancer Res. 2012;32:195-9.

16. Mesia R, Rueda A, Vera R, et al. Adjuvant therapy with cetuximab for locally advanced squamous cell carcinoma of the oropharynx: results from a randomized, phase II prospective trial. Ann Oncol. 2013;24:448-53.

17. Granados Garcia M, Chilaca Rosas MF, Lavin Lozano AJ, et al. Cetuximab concomitant with gemcitabine and radiotherapy in advanced squamous cell carcinomas of upper aerodigestive tract: a pilot study. Clin Transl Oncol. 2011;13:109-14.

18. Egloff AM, Lee JW, Langer CJ, et al. Phase II study of cetuximab in combination with cisplatin and radiation in unresectable, locally advanced head and neck squamous cell carcinoma: Eastern cooperative oncology group trial E3303. Clin Cancer Res. 2014;20:5041-51.

19. Harari PM, Harris J, Kies MS, et al. Postoperative chemoradiotherapy and cetuximab for high-risk squamous cell carcinoma of the head and neck: Radiation Therapy Oncology Group RTOG-0234. J Clin Oncol. 2014;32:2486-95. 
20. Merlano M, Russi E, Benasso M, et al. Cisplatin-based chemoradiation plus cetuximab in locally advanced head and neck cancer: a phase II clinical study. Ann Oncol. 2011;22:712-7.

21. Suntharalingam M, Kwok Y, Goloubeva O, et al. Phase II study evaluating the addition of cetuximab to the concurrent delivery of weekly carboplatin, paclitaxel, and daily radiotherapy for patients with locally advanced squamous cell carcinomas of the head and neck. Int J Radiat Oncol Biol Phys. 2012;82:1845-50.

22. Kao J, Genden EM, Gupta V, et al. Phase 2 trial of concurrent 5-fluorouracil, hydroxyurea, cetuximab, and hyperfractionated intensity-modulated radiation therapy for locally advanced head and neck cancer. Cancer. 2011;117:318-26.

23. Levy AR, Johnston KM, Sambrook J, et al. Indirect comparison of the efficacy of cetuximab and cisplatin in squamous cell carcinoma of the head and neck. Curr Med Res Opin. 2011;27:2253-9.

24. Vermorken JB, Trigo J, Hitt R, et al. Open-label, uncontrolled, multicenter phase II study to evaluate the efficacy and toxicity of cetuximab as a single agent in patients with recurrent and/or metastatic squamous cell carcinoma of the head and neck who failed to respond to platinum-based therapy. J Clin Oncol. 2007;25:2171-7.

25. Vermorken JB, Herbst RS, Leon X, Amellal N, Baselga J. Overview of the efficacy of cetuximab in recurrent and/or metastatic squamous cell carcinoma of the head and neck in patients who previously failed platinum-based therapies. Cancer. 2008;112:2710-9.

26. Yoshino T, Hasegawa Y, Takahashi S, et al. Platinum-based chemotherapy plus cetuximab for the first-line treatment of Japanese patients with recurrent and/or metastatic squamous cell carcinoma of the head and neck: results of a phase II trial. Jpn J Clin Oncol. 2013;43:524-31.

27. Guo Y, Shi M, Yang A, et al. Platinum-based chemotherapy plus cetuximab first-line for Asian patients with recurrent and/or metastatic squamous cell carcinoma of the head and neck: Results of an open-label, single-arm, multicenter trial. Head Neck. 2015;37:1081-7.

28. de Mello RA, Geros S, Alves MP, Moreira F, Avezedo I, Dinis J. Cetuximab plus platinum-based chemotherapy in head and neck squamous cell carcinoma: a retrospective study in a single comprehensive European cancer institution. PLoS One. 2014;9:e86697.

29. Burtness B, Goldwasser MA, Flood W, Mattar B, Forastiere AA; Eastern Cooperative Oncology G. Phase III randomized trial of cisplatin plus placebo compared with cisplatin plus cetuximab in metastatic/recurrent head and neck cancer: an Eastern Cooperative Oncology Group study. J Clin Oncol. 2005;23:8646-54.

30. Baselga J, Trigo JM, Bourhis J, et al. Phase II multicenter study of the antiepidermal growth factor receptor monoclonal antibody cetuximab in combination with platinum-based chemotherapy in patients with platinum-refractory metastatic and/or recurrent squamous cell carcinoma of the head and neck. J Clin Oncol. 2005;23:5568-77.

31. Vermorken JB, Mesia R, Rivera F, et al. Platinum-based chemotherapy plus cetuximab in head and neck cancer. N Engl J Med. 2008;359:1116-27.

32. Hitt R, Irigoyen A, Cortes-Funes $\mathrm{H}$, et al. Phase II study of the combination of cetuximab and weekly paclitaxel in the first-line treatment of patients with recurrent and/or metastatic squamous cell carcinoma of head and neck. Ann Oncol. 2012;23:1016-22.

33. Jimenez B, Trigo JM, Pajares BI, et al. Efficacy and safety of weekly paclitaxel combined with cetuximab in the treatment of pretreated recurrent/metastatic head and neck cancer patients. Oral Oncol. 2013;49:182-5.

34. Peron J, Ceruse P, Lavergne E, et al. Paclitaxel and cetuximab combination efficiency after the failure of a platinum-based chemotherapy in recurrent/metastatic head and neck squamous cell carcinoma. Anticancer Drugs. 2012;23:996-1001.

35. Knoedler M, Gauler TC, Gruenwald V, et al. Phase II study of cetuximab in combination with docetaxel in patients with recurrent and/or metastatic squamous cell carcinoma of the head and neck after platinum-containing therapy: a multicenter study of the Arbeitsgemeinschaft Internistische Onkologie. Oncology. 2013;84:284-9.
36. Guigay J, Fayette J, Dillies AF, et al. Cetuximab, docetaxel, and cisplatin as first-line treatment in patients with recurrent or metastatic head and neck squamous cell carcinoma: a multicenter, phase II GORTEC study. Ann Oncol. 2015;26:1941-7.

37. Jensen AD, Bergmann ZP, Garcia-Huttenlocher H, Freier K, Debus J, Munter MW. Cetuximab and radiation for primary and recurrent squamous cell carcinoma of the head and neck (SCCHN) in the elderly and multi-morbid patient: a single-centre experience. Head Neck Oncol. 2010;2:34.

38. Balermpas P, Keller C, Hambek M, et al. Reirradiation with cetuximab in locoregional recurrent and inoperable squamous cell carcinoma of the head and neck: feasibility and first efficacy results. Int J Radiat Oncol Biol Phys. 2012;83:e377-83.

39. Heron DE, Rwigema JC, Gibson MK, Burton SA, Quinn AE, Ferris RL? Concurrent cetuximab with stereotactic body radiotherapy for recurrent squamous cell carcinoma of the head and neck: a single institution matched case-control study. Am J Clin Oncol. 2011;34:165-72.

40. Lartigau EF, Tresch E, Thariat J, et al. Multi institutional phase II study of concomitant stereotactic reirradiation and cetuximab for recurrent head and neck cancer. Radiother Oncol. 2013;109:281-5.

41. Vargo JA, Ferris RL, Ohr J, et al. A prospective phase 2 trial of reir radiation with stereotactic body radiation therapy plus cetuximab in patients with previously irradiated recurrent squamous cell carcinoma of the head and neck. Int J Radiat Oncol Biol Phys. 2015;91:480-8.

42. Vargo JA, Kubicek GJ, Ferris RL, et al. Adjuvant stereotactic body radiotherapy+/-cetuximab following salvage surgery in previously irradiated head and neck cancer. Laryngoscope. 2014;124:1579-84.

43. Russi EG, Moretto F, Rampino M, et al. Acute skin toxicity management in head and neck cancer patients treated with radiotherapy and chemotherapy or EGFR inhibitors: Literature review and consensus. Crit Rev Oncol Hematol. 2015;96:167-82.

44. Bernier J, Russi EG, Homey B, et al. Management of radiation dermatitis in patients receiving cetuximab and radiotherapy for locally ad vanced squamous cell carcinoma of the head and neck: proposals for a revised grading system and consensus management guidelines. Ann Oncol. 2011;22:2191-200.

45. Taberna M, Rullan AJ, Hierro C, et al. Late toxicity after radical treatment for locally advanced head and neck cancer. Oral Oncol. 2015; 51:795-9.

46. Curran D, Giralt J, Harari PM, et al. Quality of life in head and neck cancer patients after treatment with high-dose radiotherapy alone or in combination with cetuximab. J Clin Oncol. 2007;25:2191-7.

47. Mesia R, Rivera F, Kawecki A, et al. Quality of life of patients receiving platinum-based chemotherapy plus cetuximab first line for recurrent and/or metastatic squamous cell carcinoma of the head and neck. Ann Oncol. 2010;21:1967-73.

48. Ceruse $\mathrm{P}$, Cosmidis $\mathrm{A}$, Belot $\mathrm{A}$, et al. A pyriform sinus cancer organ preservation strategy comprising induction chemotherapy with docetaxel, cisplatin, and 5-fluorouracil, followed by potentiated radiotherapy: a multicenter, retrospective study. Anticancer Drugs. 2014;25:970-5.

49. Bernier J, Domenge C, Ozsahin M, et al. Postoperative irradiation with or without concomitant chemotherapy for locally advanced head and neck cancer. N Engl J Med. 2004;350:1945-52.

50. Leon X, Aguero A, Lopez M, et al. Salvage surgery after local recur rence in patients with head and neck carcinoma treated with chemoradiotherapy or bioradiotherapy. Auris Nasus Larynx. 2015;42:145-9.

51. Brown B, Diamantopoulos A, Bernier J, et al. An economic evaluation of cetuximab combined with radiotherapy for patients with locally advanced head and neck cancer in Belgium, France, Italy, Switzerland, and the United Kingdom. Value Health. 2008;11:791-9.

52. van der Linden N, van Gils CW, Pescott CP, Buter J, Vergeer MR, Groot CA. Real-world cost-effectiveness of cetuximab in locally advanced squamous cell carcinoma of the head and neck. Eur Arch Otorhinolaryngol. 2015;272:2007-16. 